\title{
STUDY OF THE STRUCTURAL, OPTICAL, ELECTRICAL AND MORPHOLOGICAL PROPERTIES OF NICKEL SULFIDE THIN FILMS USED IN SUPERCAPACITORS
}

\author{
Abdelouahab Gahtar ${ }^{1,2 *}$, Said Benramache ${ }^{1}$, Abdelkader Ammari ${ }^{3}$, Abdelwaheb \\ Boukhachem $^{4}$
}

${ }^{I}$ Department of Material Sciences, Faculty of Sciences, University of Biskra, Algeria.

${ }^{2}$ Department of Biology, Faculty of Sciences, University of Hamma Lakhder, El Oued, Algeria.

${ }^{3}$ Department of Physics, Faculty of Matter Sciences, Ibn-Khaldoun University, Tiaret, Algeria

${ }^{4}$ Unité de physique des dispositifs à semi-conducteurs. Faculté des sciences de Tunis. Université de

Tunis El Manar. 2092 Tunis - Tunisia.

*Corresponding author: abdelouahab-gahtar@univ-eloued.dz

\begin{tabular}{|c|c|}
\hline Article Info & Abstract \\
\hline $\begin{array}{l}\text { Received: } 09.11 .2020 \\
\text { Accepted: } 27.01 .2021 \\
\text { Keywords: } \\
\text { NiS; spray-pyrolysis; thin } \\
\text { films; optical gap; } \\
\text { conductivity }\end{array}$ & $\begin{array}{l}\text { Nickel sulfide (NiS) thin film has been deposited on glass substrates by spray- } \\
\text { pyrolysis at } 325 \pm 5{ }^{\circ} \mathrm{C} \text {. The precursor aqueous solution was synthetized using } \\
\text { hexahydrated nickel nitrates and thiourea. The structural, morphological, optical } \\
\text { and electrical properties were characterized using X-ray diffraction (XRD), } \\
\text { scanning electron microscopy (SEM), UV-visible spectroscopy and four probes } \\
\text { electrical measurements. The XRD analysis confirmed the hexagonal structure of } \\
\text { NiS thin film, which was found to crystalize along [010] direction with an average } \\
\text { crystallites size of } 10.5 \mathrm{~nm} \text {. The lattice parameters are a }=\mathrm{b}=3.420 \AA \text { and } \mathrm{c}= \\
5.300 \AA \text { in the space group P6 } 3 / \text { mmc. The optical properties of the films were } \\
\text { investigated through the transmittance and the reflectance measurements. The } \\
\text { results revealed that the material exhibits a direct optical band gap of } 1.03 \mathrm{eV} \text {. The } \\
\text { elementary composition analysis confirmed the presence of Ni and S with a } \\
\text { stoichiometry ratio (Ni/S) of } 1.05 \text {. The morphology analysis revealed a } \\
\text { homogenous crack-free, compact appearance and a granular surface in all scanned } \\
\text { areas. The average roughness of the surface was } 6.48 \text { nm. On the other hand, the } \\
\text { film exhibits a high electrical conductivity ca. } 1.10 \times 10^{5} \mathrm{~S} / \mathrm{cm} \text { at room } \\
\text { temperature. The above results show that the prepared NiS in this study has a good } \\
\text { crystallization, dense morphology, good stoichiometric ratio and high conductivity; } \\
\text { therefore, it stands as a potential candidate for application in supercapacitors as an } \\
\text { electrode material. }\end{array}$ \\
\hline
\end{tabular}

\section{Introduction}

Recently, transition metal sulfides (TMS) has become one of the subjects of great interest to researchers due to the high electrical conductivity [1], good electrochemical 
stability [2], respect for the environment and low cost of production [3]. Some (TMS) such as $\mathrm{NiS}, \mathrm{CoS}, \mathrm{SnS}, \mathrm{CuS}$ and $\mathrm{ZnS}$ have been widely exploited as new electrode materials for supercapacitors due to their distinctive properties compared to the oxides and hydroxides of these minerals [4]. In the TMS family, Nickel sulfide (NiS) belongs to the semiconducting compounds VIII-VI. Furthermore, the NiS depicts a metallic transition induced by doping and an antiferromagnetic behavior at high temperatures [5].

NiS exists in two phases: hexagonal structure $(\alpha-\mathrm{NiS})$ and rhombohedral structure $(\beta$ $\mathrm{NiS})$. In literature thin films of NiS have been deposited by different methods such as spraypyrolysis [6], chemical bath deposition (CBD) [5], hydrothermal [7], successive ionic layer adsorption and reaction (SILAR) [8], thermal evaporation [9], electro-deposition [10] and sol-gel [11]. The present study deals with the synthesis and the characterization of the structural, optical, morphological and electrical properties of the $\alpha$ - NiS phase deposited by spray-pyrolysis at $325^{\circ} \mathrm{C}$.

\section{Experimental details}

\subsection{Preparation of nickel sulfide (NiS)}

NiS was deposited on a well-cleaned glass substrate using spray-pyrolysis technique. The precursor solution consisted of nickel nitrates hyxahydrate $\left(\mathrm{Ni}\left(\mathrm{NO}_{3}\right)_{2} .6 \mathrm{H}_{2} \mathrm{O} ; 10^{-1} \mathrm{~mol} / \mathrm{l}\right)$ and thiourea $\left(\mathrm{CS}\left(\mathrm{NH}_{2}\right)_{2} ; 2 \times 10^{-1} \mathrm{~mol} / \mathrm{l}\right)$, dissolved in $100 \mathrm{ml}$ of ionized water. A few drops of acitic acid were added for complete dissolution. The temperature of the substrate was fixed at $325 \pm 5{ }^{\circ} \mathrm{C}$, prior to deposition and compressed air was used as a vector gas to produce aerosol particles. The flow rate was kept at 0.5 bar. The distance between the nebulizer and the substrate was set at $25 \mathrm{~cm}$. In order to achieve uniform deposits, the spray gun of the nebulizer is connected to a manually operated stepper motor to control the position of the spray in the plane $(\mathrm{X}, \mathrm{Y})$. After deposition, the film was slowly cooled to room temperature under ambient air. The characterization was conducted on the film without any thermal treatment. The films thickness was estimated using the weight method using the following formula [12]:

$$
\mathrm{e}=\frac{\mathrm{m}}{\rho \times \mathrm{S}}
$$

where: $e$ is film thickness of the film, $m$ is mass deposited on the substrate, $S$ is the area of the film and $\rho$ is the density of $\mathrm{NiS}\left(5.50 \mathrm{~g} / \mathrm{cm}^{3}\right.$ [13]). It was found to be $\sim 936 \mathrm{~nm}$. 


\section{2. Characterization}

The structural analysis was carried out using an X-ray diffractometer (DRX; Mini FlexRigaku) with a $\mathrm{Cu}-\mathrm{K}_{\alpha}$ radiation $\left(\lambda=1.5418 \AA\right.$ ) in the range of $20-60^{\circ}$, using the BrentanoBragg geometry. The morphology of the surface was analyzed using a scanning electron microscope (SEM; Qanta 350) equipped with an energy dispersive spectrometer (EDS) for elementary analysis. The surface roughness was investigated using an atomic force microscope (AFM type VEECO digital instrument). A dual-beam UV-visible spectrophotometer (UV-3101; Shimadzu), was used to measure the transmittance and reflectance in the wavelength range of $300-1100 \mathrm{~nm}$ with a resolution of $5 \mathrm{~nm}$. The electrical measurements were recorded using the four-probe method.

\section{Results and Discussions}

\subsection{X-Ray Diffraction}

Fig. 1 shows the XRD pattern of NiS prepared by the spray-pyrolysis technique. It is observed that the obtained film is polycrystalline and crystalize in a hexagonal structure (Space group No. 194: $P 6_{3} / \mathrm{mmc}$ ) strongly oriented along (010) direction. The intensity of the reflection on this plane is greater than that of the other diffraction peaks corresponding to (011), (012) and (110) plans. The XRD pattern was indexed according to the JCPDS card \#98-064-6340. The Wyckoff positions of $\mathrm{Ni}$ and $\mathrm{S}$ ions are given in table 1.

Table 1: Wyckoff positions of Ni and S ions in the hexagonal structure.

\begin{tabular}{|c|c|c|c|c|c|c|}
\hline Ion & Ox & Wyck & Site & $\mathbf{x} / \mathbf{a}$ & $\mathbf{y} / \mathbf{b}$ & $\mathbf{z} / \mathbf{c}$ \\
\hline Ni1 & 2 & 2a & $-3 \mathrm{~m}$. & 0 & 0 & 0 \\
\hline S1 & -2 & 2c & $-6 \mathrm{~m} 2$ & $1 / 3$ & $2 / 3$ & $1 / 4$ \\
\hline
\end{tabular}

On the other hand, the broad band observed on the XRD pattern is due partially to the amorphous phase; thus, confirming the formation of polycrystalline layer. The data obtained in this study are also in a good agreement with the previous reports in the literature on NiS films prepared by spray-pyrolysis and other techniques $[6,14,15]$. 


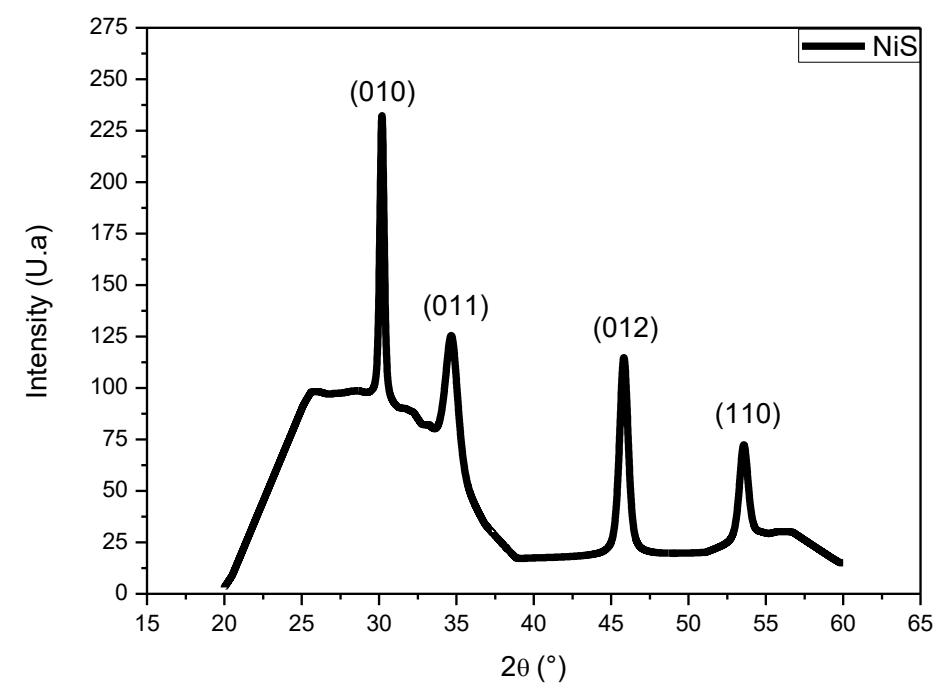

Fig. 1. X-ray pattern of NiS thin film.

The unit cell parameters $\mathrm{a}, \mathrm{b}$ and $\mathrm{c}$, were determined using the following formula [16]:

$$
\frac{1}{\mathrm{~d}_{\mathrm{hkl}}^{2}}=\frac{3}{4}\left(\frac{\mathrm{h}^{2}+\mathrm{k}^{2}+\mathrm{hk}}{\mathrm{a}^{2}}\right)+\frac{\mathrm{l}^{2}}{\mathrm{c}^{2}}
$$

The unit cell volume was evaluated using the following formula:

$$
V=a^{2} \times c \times \sin \left(60^{\circ}\right)
$$

Table 2 summarizes the structural parameters compared to those of the corresponding JCPDS card. The results are in good agreement with the standard card (JCPDS card No. 98064-6340). The slight mismatch suggests the presence of structural disorder in the film.

Table 2: Lattice parameters ( $a, b$ and $c)$ and the unit cell Volume (V) compared to the data of JCPDS card.

\begin{tabular}{|c|c|c|c|c|c|c|}
\hline \multicolumn{3}{|c|}{ Our data } & \multicolumn{3}{c|}{ JCPDS card } & \multirow{2}{*}{$\mathrm{V}\left(\AA^{3}\right)$} \\
\cline { 1 - 5 } $\mathrm{a}=\mathrm{b}(\AA)$ & $\mathrm{c}(\AA)$ & $\mathrm{c} / \mathrm{a}$ & $\mathrm{a}=\mathrm{b}(\AA)$ & $\mathrm{c}(\AA)$ & $\mathrm{c} / \mathrm{a}$ & 53.202 \\
\hline 3.412 & 5.277 & 1.546 & 3.420 & 5.300 & 1.550 & 5 \\
\hline
\end{tabular}

The ratio (c/a) of 1.546 is slightly smaller than the standard value (1.550) of the hexagonal structure. This may be due to vacancies in the lattice that cause local changes and 
contraction of the lattice. The inter-plans distance $\left(\mathrm{d}_{\mathrm{hkl}}\right)$ was calculated using Bragg formula [17] .

$$
2 \mathrm{~d}_{\mathrm{hkl}} \sin \theta=\mathrm{n} \lambda
$$

On the other hand, the texture coefficient $\left(\mathrm{TC}_{\mathrm{hkl}}\right)$, which is calculated in terms of the intensity of each orientation $\left(\mathrm{I}_{\mathrm{hkl}}\right)$, gives information on the probability of the growth according to an orientation (hkl). This coefficient is given by the following relation [18]:

$$
\mathrm{TC}_{\mathrm{hkl}}=\frac{\mathrm{I}_{\mathrm{hkl}} / \mathrm{I}_{0 \mathrm{hkl}}}{\mathrm{N}^{-1}\left[\sum_{\mathrm{i}=1}^{\mathrm{n}} \frac{\mathrm{I}_{\mathrm{hkl}}}{\mathrm{I}_{0 \mathrm{hkl}}}\right]}
$$

where: Iohkl is the intensity according to the JCPDS card of the plan (hkl) and $\mathrm{N}$ is the number of diffraction peaks. The obtained values of $\mathrm{TC}_{\mathrm{hkl}}$ are gathered in Table 3 . It is observed that the value of the largest texture coefficient corresponds to the peak (010), which indicates that it is the preferred orientation. Hence, the peak (010) has the highest intensity when compared to the other peaks.

The crystallites size (D) was estimated for all diffraction peaks using Debye formula [19]:

$$
\mathrm{D}=\frac{\mathrm{k} \times \mathrm{l}}{\beta_{1 / 2} \cos \theta}
$$

where: $\mathrm{k}$ is a constant $(\mathrm{k}=0.90), \beta_{1 / 2}$ is the full width at half the maximum of the diffraction peak, $\theta$ is the Bragg angle for each plan (hkl) and $\lambda=1.5406 \AA$ is the wavelength of the X-ray radiation used.

The residual stress $\left(\varepsilon_{\mathrm{hkl}}\right)$ and the dislocation density $\left(\delta_{\mathrm{hkl}}\right)$ in the film were evaluated using the following formulas [20] :

$$
\left\{\begin{array}{l}
\delta=\frac{1}{\mathrm{D}^{2}} \\
\varepsilon=\frac{\beta_{1 / 2}}{4 \tan \theta}
\end{array}\right.
$$


Table 3: Texture coefficient $\left(T C_{h k l}\right)$, crystallites size $\left(D_{h k l}\right)$, residual stress $\left(\varepsilon_{h k l}\right)$ and dislocation density $\left(\delta_{h k l}\right)$.

\begin{tabular}{|c|c|c|c|c|c|}
\hline$(\mathrm{hkl})$ & $\mathrm{d}_{\mathrm{hkl}}(\mathrm{nm})$ & $\mathrm{D}_{\mathrm{hkl}}(\mathrm{nm})$ & $\varepsilon_{\mathrm{hkl}} \times 10^{-3}$ & $\begin{array}{c}\delta_{\mathrm{hkl}} \times 10^{15} \\
\left(\text { lines } / \mathrm{nm}^{2}\right)\end{array}$ & $\mathrm{TC}$ hkl \\
\hline 010 & 0.296 & 28.015 & 0.509 & 1,274 & 0.893 \\
\hline 011 & 0.258 & 9.446 & 13.207 & 11.206 & 0.404 \\
\hline 012 & 0.198 & 14.680 & 6.508 & 4.639 & 0.605 \\
\hline 110 & 0.171 & 15.146 & 5.448 & 4.358 & 0.297 \\
\hline
\end{tabular}

In addition, the average crystallites size $\prec D \succ$, micro-stress $\prec \varepsilon \succ$ and the dislocation density $\prec \delta \succ$ can be determined using the texture coefficient according to the formulas [6]:

$$
\left\{\begin{array}{l}
\langle\mathrm{D}\rangle=\frac{\sum \mathrm{TC}_{\mathrm{hkl}} \times \mathrm{D}_{\mathrm{hkl}}}{\mathrm{n}} \\
\langle\varepsilon\rangle=\frac{\sum \mathrm{TC}_{\mathrm{hkl}} \times \varepsilon_{\mathrm{hkl}}}{\mathrm{n}} \\
\langle\delta\rangle=\frac{\sum \mathrm{TC}_{\mathrm{hkl}} \times \delta_{\mathrm{hkl}}}{\sum \mathrm{TC}_{\mathrm{hkl}}}
\end{array}\right.
$$

The average values of the crystallites size, micro-stress and the dislocation density are $10.5 \mathrm{~nm}, 3.865 \times 10^{-3}$ and $4.442 \times 10^{15}$ (lines $/ \mathrm{nm}^{2}$ ), respectively. The obtained values are compatible with a high quality thin film. It is a well-established fact that the dislocations in the film acquire more energy and exhibit higher mobility during crystallization. These activated dislocations segregate towards the grains boundaries and are neutralized as the crystallization of the film proceeds.

\subsection{Optical properties}

Fig. 2 shows the transmission and reflectance spectra of NiS recorded at room temperature. It observed that both transmittance and reflectance decrease in the ultra-violet range. However, an enhancement of the transparence of the film is observed above $400 \mathrm{~nm}$ owing to a reduced scattering effect and propagation losses. The average optical transmittance and reflectance are about $0.62 \%$ and $1.10 \%$ respectively. Moreover, the absence of the interference fringes in the long wavelength region is mainly due to the roughness of the film. 


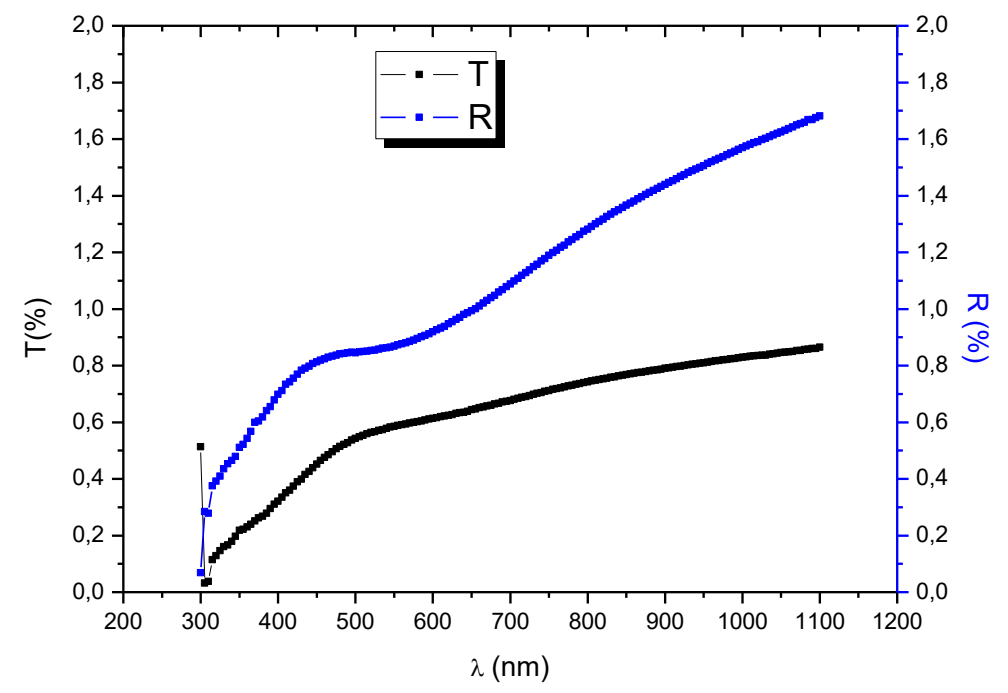

Fig. 2. UV-visible reflectance and transmittance spectra of NiS thin film.

Furthermore, it is observed that the film reflectance is higher than its transmittance. This phenomenon can be related to the oscillation of the free carriers plasma, depicting the metallic behavior of the film [6]. The absorption coefficient $(\alpha)$ was calculated from the transmittance and the reflectance spectra, using the following formula [21]:

$$
\alpha=\frac{1}{\mathrm{e}} \ln \left(\frac{(1-\mathrm{R})^{2}}{\mathrm{~T}}\right)
$$

where: $d$ is the thickness, $\mathrm{R}$ is the reflectance and $\mathrm{T}$ is the transmittance. Fig. 3 shows the variation of the absorption coefficient $(\alpha)$ as a function of wavelength $(\lambda)$. The average absorption coefficient is $4.12 \times 10^{4} \mathrm{~cm}^{-1}$, which is of the same order of magnitude observed in semiconducting reflecting thin films and it is close to those reported in the literature for semiconducting thin films [22].

The optical band gap of the material was determined using Tauc formula [23]:

$$
\alpha h v=B\left(h v-E_{g}\right)^{p}
$$

where: $B$ is a constant, $p$ is an integer that takes the value $1 / 2$ or 2 for direct or indirect transitions, respectively. Fig. 4 shows the plot of $(\alpha h v)^{2}$ versus energy $(h v)$. 


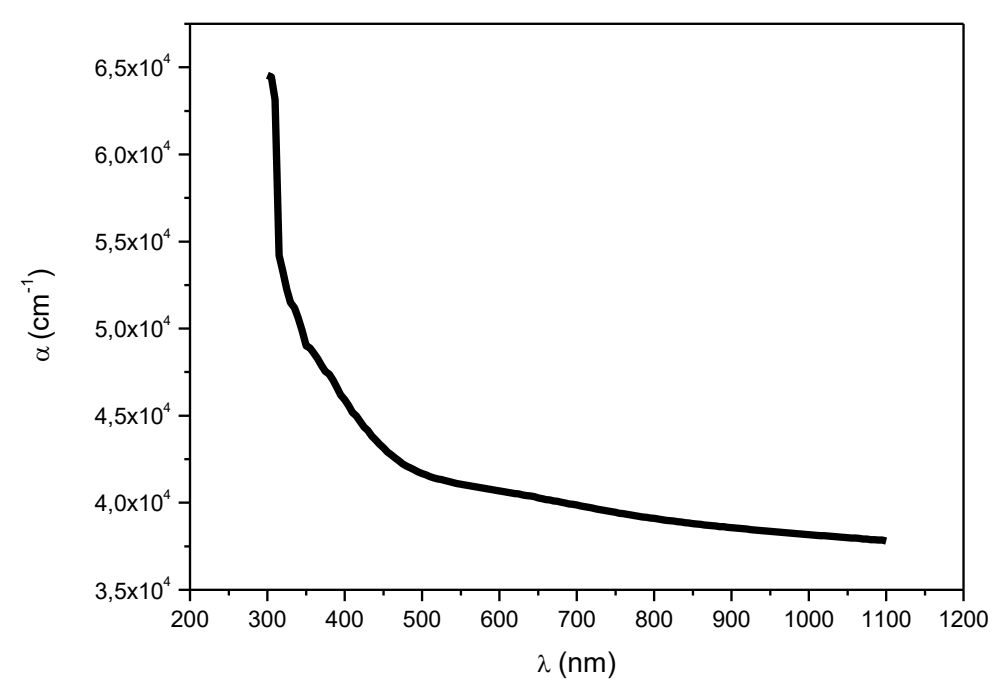

Fig. 3. Evolution of the absorption coefficient $(\alpha)$ of NiS thin film.

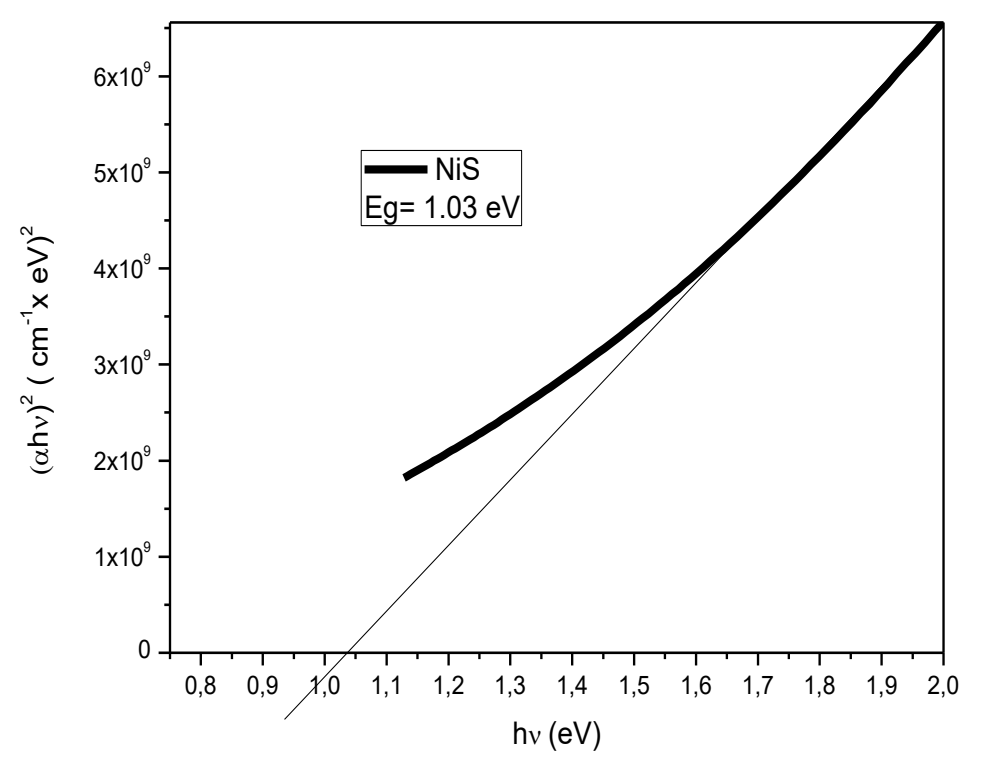

Fig. 4. Plots of $(\alpha h v)^{2}$ versus photon energy (hv) of NiS thin film.

The linear extrapolation of the curve yields the intersection point with the abscissa axis, which corresponds to the energy of the optical transition. The optical band gap of the film was found to be $1.03 \mathrm{eV}$, in a good agreement with the values reported in the literature [22]. In addition, the value of the optical gap agrees with the structural analysis, which is blue shifted when compared to that of the bulk material, nearby $0.8 \mathrm{eV}$. This blue shift of $\sim 230$ $\mathrm{meV}$ of the band edges can be understood if we consider the quantum confinement pooled alongside with the Moss-Burstein effect. Therefore, an additional energy is required for the 
electronic transition due to the band filling of the band edges in addition to the shift due to the particle size [24].

\subsection{Electrical studies}

The electrical conductivity of NiS was determined by the four-points probe method, it is based on the measured sheet resistance of the films as expressed by the following formula [25]:

$$
\left\{\begin{array}{l}
R_{s h}=\frac{\pi}{\ln 2} \times \frac{V}{I} \\
\sigma=\frac{1}{\rho}=\frac{1}{e \times R_{s h}}
\end{array}\right.
$$

where: $\rho$ is the electrical resistivity, e is the film thickness, $\mathrm{I}$ is the applied currant $=1 \mathrm{nA}$ and $\mathrm{V}$ is the measurement voltage. Table 4 summarizes the results of the electrical measurements.

Table 4: The electrical parameters of NiS.

\begin{tabular}{|c|c|c|c|c|}
\hline Thin film & $\begin{array}{c}\text { Film thickness } \\
\mathbf{e}(\mathbf{n m})\end{array}$ & $\begin{array}{c}\text { Sheet resistance } \\
\boldsymbol{R}_{\boldsymbol{s h}} \mathbf{( \Omega / \mathbf { s q } )}\end{array}$ & $\begin{array}{c}\text { Electrical resistivity } \\
\boldsymbol{\rho}(\mathbf{\Omega . c m})^{-\mathbf{1}}\end{array}$ & $\begin{array}{c}\text { Electrical } \\
\text { conductivity } \boldsymbol{\sigma}(\mathbf{S} / \mathbf{c m})\end{array}$ \\
\hline $\mathrm{NiS}$ & 936.253 & $9.74 \times 10^{-2}$ & $9.11 \times 10^{-6}$ & $1.10 \times 10^{5}$ \\
\hline
\end{tabular}

It is observed that the film exhibits a very high electrical conductivity of $1.10 \times 10^{5}$ $(\mathrm{S} / \mathrm{cm})$. Thus, confirming the metallic behavior of the prepared NiS, which support the above claim about the Moss-Burstein effect. Also, these results are close to the reported data in the literature $[26,27]$. It is evident that the NiS prepared in this study is highly attractive as an electrode material for application in supercapacitors.

\subsection{SEM and EDS analysis}

Fig. 5 shows the SEM and EDS micrographs of NiS thin films. The SEM micrograph show that the surface of the film is rough, porous and granular with a random distribution. This morphology yields a greater surface/volume ratio and thus, the specific surface of the film is higher when compared to that of a smooth film. In addition, it is observed that the film was homogenously deposited without micro-cracks. 


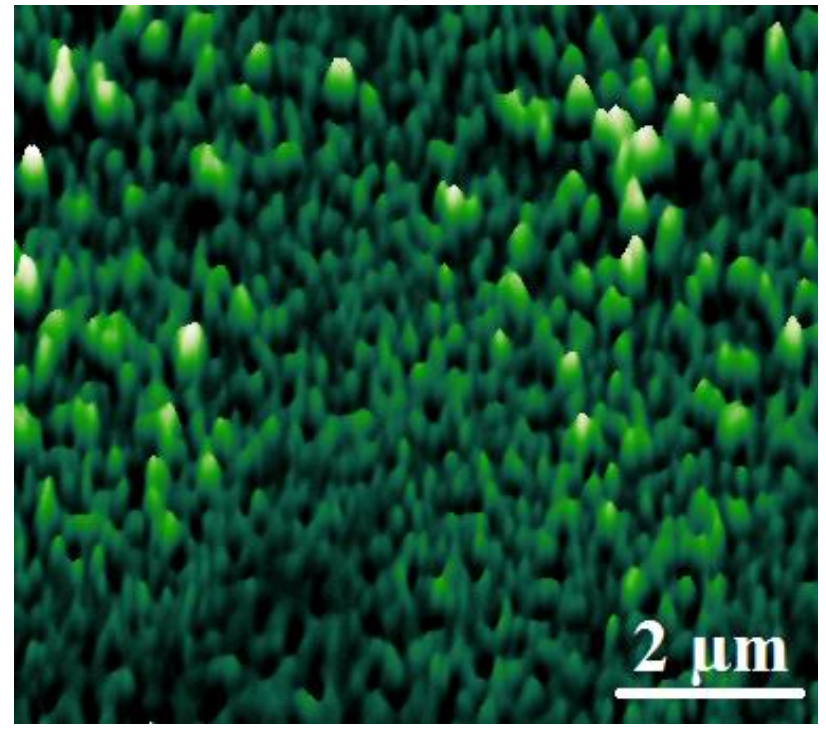

(a)

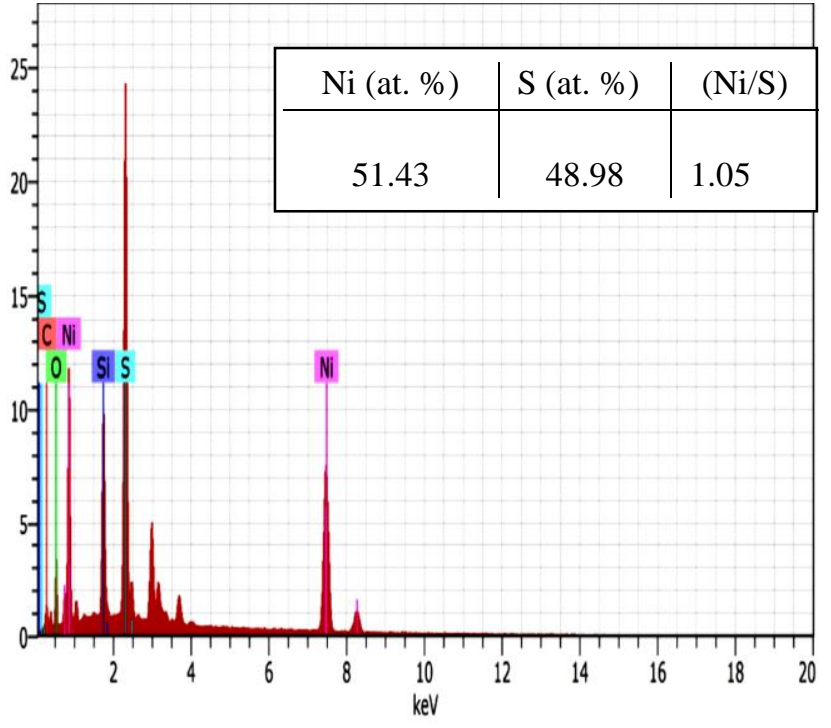

(b)

Fig. 5. (a) SEM image and (b) EDS analysis of NiS thin film

The EDS micrograph of the films (Fig. 5 b), confirm the presence of Ni and S elements with an atomic ratio of 1.05 . Furthermore, the analysis revealed the presence of other elements such as oxygen $(\mathrm{O})$ and silicon $(\mathrm{Si})$ which originate from the $\mathrm{SiO}_{2}$ glass substrate. While, the presence of carbon $\mathrm{C}$ is probably due to thiourea $\left(\mathrm{SC}\left(\mathrm{NH}_{2}\right)_{2}\right)$ involved in the synthesis. It is pertinent to note that the atomic percentage of nickel to sulfur is almost equal to 1 , suggesting the formation of a sulfur-poor surface; this is due to the property of sulfur to be volatile at high temperatures.

\section{5. AFM analysis}

The surface roughness is an important physical parameter in some properties, especially optical scattering. Fig. 6 ( $a$ and $b$ ) shows 2D and 3D micrographs of the NiS surface, recorded in a scanning area of $1 \times 1 \mu \mathrm{m}^{2}$. The surface depicts a granular and dense morphology. The analysis of the surface profile yields the average roughness $\left(R_{a}\right)$ and root mean square roughness $\left(\mathrm{R}_{\mathrm{RMS}}\right)$, the geometric mean of the heights of all points on the surface scanned by the microscope. These parameters are defined as follows [18]:

$$
\left\{\begin{array}{l}
\mathrm{R}_{\mathrm{a}}=\frac{1}{\mathrm{l}} \int_{0}^{\mathrm{l}}\left|\mathrm{z}-\mathrm{z}_{\mathrm{i}}\right| \mathrm{dx} \\
\mathrm{R}_{\mathrm{RMS}}=\sqrt{\frac{1}{\mathrm{l}} \int_{0}^{\mathrm{l}}\left|\mathrm{z}-\mathrm{z}_{\mathrm{i}}\right|^{2} \mathrm{dx}}
\end{array}\right.
$$


where: $l$ is the length of the sample, $Z_{i}$ is the height reference and $Z$ is the profile value. The values of $R_{R M S}$ and $R_{a}$ were found to be 8.07 and $6.48 \mathrm{~nm}$, respectively. It can be observed that both $\mathrm{R}_{\mathrm{a}}$ and $\mathrm{R}_{\mathrm{RMS}}$ are very small when compared to the thickness of the film i.e. $\left(\mathrm{R}_{\mathrm{a}}\right.$, $\left.\mathrm{R}_{\mathrm{RMS}}\right)<<$ e. Thus, the surface is very smooth and suitable for use in microelectronic and optoelectronic devices [28].

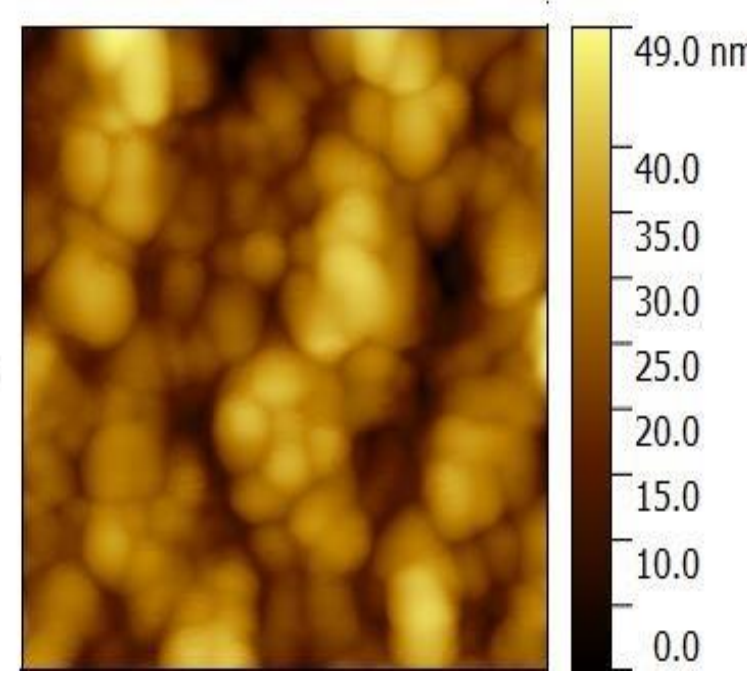

(a)

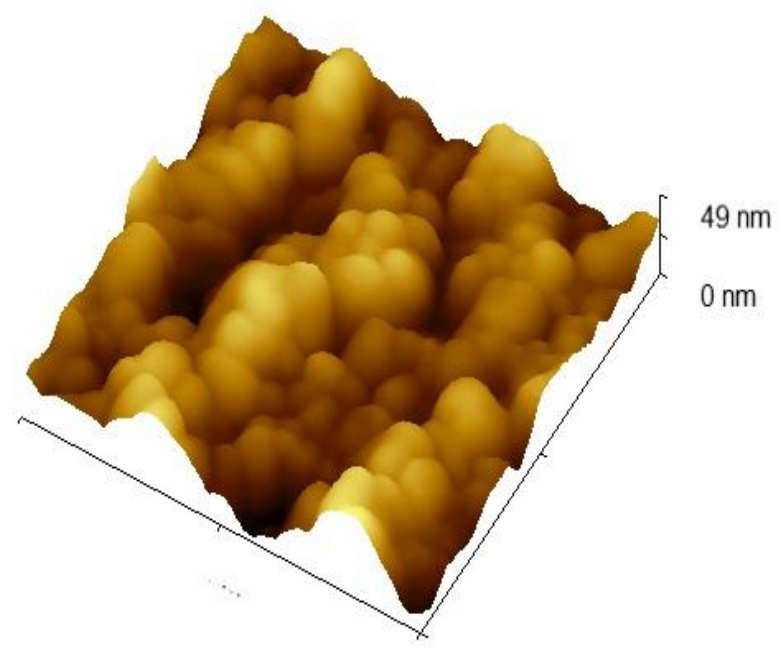

(b)

Fig. 6. (a) 2D and (b) 3D-AFM images of NiS thin film.

\section{Conclusion}

In the present study, we have successfully deposited at $325^{\circ} \mathrm{C}$ the $\alpha$-phase of nickel sulfide (NiS) using spray-pyrolysis technique. Then, the film was characterized without any post-thermal treatment. The morphology analysis showed that the surface is smooth, dense and granular. the elementary analysis confirmed the presence of $\mathrm{Ni}$ and $\mathrm{S}$ with an atomic ratio of 1.05. The XRD analysis confirmed the polycrystalline character of the film with a hexagonal structure oriented along (010) direction. The average crystallites size was found to be $10.5 \mathrm{~nm}$. The optical analysis demonstrated the metallic behavior of the film with an average reflectance of $1.10 \%$ in the visible range and a direct optical band gap of $1.03 \mathrm{eV}$. Furthermore, the film exhibits a very high electrical conductivity of $1.10 \times 10^{5} \mathrm{~S} / \mathrm{cm}$ at room temperature. The above results indicate that the NiS phase prepared in this study is a good candidate as an electrode material for application in supercapacitors. 


\section{Acknowledgments}

Authors wish to thank, particularly, professor Bali Hicham for his help during the preparation of the present manuscript. Special thanks go to Dr. A. Ziouche from the Research Center in Industrial Technologies (CRTI), (Algiers) Algeria, for the Atomic force microscopy (AFM) measurements.

\section{References}

[1] S. Krishnakumar, N. Shanthi, D. Sarma, Physical Review B, 66 (2002) 105-115.

[2] S. Sahoo, K.K. Naik, D.J. Late, C.S. Rout, Journal of Alloys and Compounds, 695 (2017) 154-161.

[3] B. De, J. Balamurugan, N.H. Kim, J.H. Lee, ACS applied materials \& interfaces, 9 (2017) 2459-2468.

[4] F. Luo, J. Li, H. Yuan, D. Xiao, Electrochimica Acta, 123 (2014) 183-189.

[5] S. Suresh, S.S. Anand, R. Arul, D. Isha, Chalcogenide Letters, 13 (2016) 291-299.

[6] R. Boughalmi, R. Rahmani, A. Boukhachem, B. Amrani, K. Driss-Khodja, M. Amlouk, Materials Chemistry and Physics, 163 (2015) 99-106.

[7] A. Patil, A. Lokhande, P. Shinde, J. Kim, C. Lokhande, Journal of energy chemistry, 27 (2018) 791-800.

[8] S. Sartale, C. Lokhande, Materials Chemistry and Physics, 72 (2001) 101-104.

[9] R.K. Singh, J. Narayan, Physical Review B, 41 (1990) 8843.

[10] H. Ruan, Y. Li, H. Qiu, M. Wei, Journal of Alloys and Compounds, 588 (2014) 357-360.

[11] P. Yang, M. Lü, C.F. Song, G. Zhou, D. Xu, D.R. Yuan, Journal of Physics and Chemistry of Solids, 63 (2002) 2047-2051.

[12] V.P. Patil, S. Pawar, M. Chougule, P. Godse, R. Sakhare, S. Sen, P. Joshi, Journal of Surface Engineered Materials and Advanced Technology, 01 (2011) 35-41.

[13] R. Karthikeyan, Synthesis of Phase Controlled Nickel Sulfide Nanostructures and their Catalytic Applications, (2015).

[14] A. Ammari, M. Trari, B. Bellal, N. Zebbar, Journal of Electroanalytical Chemistry, 823 (2018) 638-646.

[15] V. Kumar, D. Sharma, K. Sharma, D. Dwivedi, Optik, 156 (2018) 43-48.

[16] B. Bharathi, S. Thanikaikarasan, P. Chandrasekar, P. Kollu, T. Mahalingam, L. Ixtlilco, Journal of New Materials for Electrochemical Systems, 17 (2014) 167-171.

[17] F. Atay, S. KÖSE, V. Bilgin, İ. AKYÜZ, Turkish Journal of Physics, 27 (2003) 285-292. 
[18] A. Boukhachem, M. Mokhtari, N. Benameur, A. Ziouche, M. Martínez, P. Petkova, M. Ghamnia, A. Cobo, M. Zergoug, M. Amlouk, Sensors and Actuators A: Physical, 253 (2017) 198-209.

[19] A. Gahtar, A. Rahal, B. Benhaoua, S. Benramache, Optik, 125 (2014) 3674-3678.

[20] M. Riahi, C. Martínez-Tomás, S. Agouram, A. Boukhachem, H. Maghraoui-Meherzi, Thin Solid Films, 626 (2017) 9-16.

[21] A. Akkari, C. Guasch, N. Kamoun-Turki, Journal of Alloys and Compounds, 490 (2010) 180-183.

[22] A. Hammad, Z. Elmandouh, H. Elmeleegi, Acta Physica Polonica A, 127 (2015) 901903.

[23] A. Gahtar, S. Benramache, B. Benhaoua, F. Chabane, Journal of Semiconductors, 34 (2013) 073002.

[24] A. Ammari, M. Trari, Colloids and Surfaces A: Physicochemical and Engineering Aspects, 561 (2019) 178-186.

[25] S. Benramache, B. Benhaoua, H. Guezzoun, Annals of West University of TimisoaraPhysics, 1 (2020).

[26] A. Gahtar, S. Benramache, C. Zaouche, A. Boukacham, A. Sayah, Advances in Materials Science, 20 (2020) 36-51.

[27] J. Ray, M. Patel, P. Ghediya, T.K. Chaudhuri, Materials Research Express, 3 (2016) 075906.

[28] K. Aboulkacem, A. Abdelkader, B. Bediaf, B. Amar, K. Abdelmalek, B. Hadj, Japanese Journal of Applied Physics, 57 (2018) 045801. 